\title{
AGRARIAN DISTRESS AND FARMER SUICIDES: ANALYSIS OF FACTORS FOR CAUSATION IN INDIA
}

\section{POUSHALI CHAKRABORTY \& VEDANT DUBEY}

Student, NMIMS Navi Mumbai School of Law, Maharastra, India

Currently, India as a nation is a service economy where 50\% of Indian population is dependent on agriculture and which makes the nation intensively dependent on agriculture; yet agriculture forms only 15.4 percent of the GDP of the nation, and there is an ever increasing inclination towards farmers' suicide. The scope of the paper thus tries to critically form an indelible link between the agricultural distress and farmers' suicide. The paper focuses on creating a link between sociological factors and psychological factors. It tries to find out the connection between the two relatable nodes and its impact on the agrarian distress and increasing farmer suicides. Further, the paper also tries to form a nexus between the farmers' suicide and the government policies. Overall, the paper through intensive research tries to find out the impact of agricultural failure on GDP of the country, touching upon both the sociological and psychological factors underlying such suicides.
\end{abstract}

KEYWORDS: Farmer Suicides, Unpredictable Natural Events \& Agriculture

Received: Mar 27, 2020; Accepted: Apr 18, 2020; Published: Jun 23, 2020; Paper Id.: IJASRJUN202014

\section{INTRODUCTION}

India is an agrarian economy with 60 percent of its people is directly dependent on agriculture. But contrary to such a robust percentage of agrarian economy, farmers' suicide account for $11.2 \%$ of all suicides in India. Amongst which, intrinsically farmers are amongst that occupational strata with high suicide risk. In spite of the occupation of farming being considered as a peaceful and healthy way of livelihood, agriculture as an occupational industry dwells in the highest mortality rate (Mc curdy \& Carroll, 2000). A recent study based on the National Crime Reports Bureau data conducted by Prof. K. Nagaraj of the Madras Institute of Development Studies points towards a proliferating figure of farmers' suicide which is 1.5 lakh farmers in totality during the period of 1995 to 2005 . Though, it is implausible to assert that NCRB publishes a full range of data, but general overview indicates a succumbing public health issue. Having made the above statement, it is rightly substantiated by various research works that the total suicide statistics in the general population are inherently under-reported succumbing to fear of legal and social ramifications, indicating uneven and distorted standards in certification and lax record-keeping by the government authorities actually impaired by prejudices, biases and corruption. Therefore, the incidence figures in government records (which indicate national annual average to be standing around 11 per 100,000 population) are much lower than recent community-based verbal autopsy studies (Das). Moreover, the suicide rates in farmers produced through government bodies/authorities depend vastly on the definition and purview of the word "farmer", and thereby, potentially leaving out the huge numbers of tenant (landless) farmers and, in particular, women farmers (Sainath, 2007). And, the above point can easily be substantiated by fact that most of the statistical data relating to farmers' suicide being preponderated by male and landholding farmers, who are sole breadwinners of their family. However, myriad of such incidents brought into light and subsequently portrayed by media shows that 
a considerable proportion of such farmers are female (Menon, 2001).

Various reasons have been attributed to such suicides, most of them being sociological and economic factors like huge mounting indebtedness, inability to pay interests, crop failure, and high cost of inputs as compared to the price of produces. However, stress has been lesser on the psychological factors, potential in contributing to farmer's suicide. Thus, the scope of this paper is about in-depth analysis of both the sociological factors as well as the psychological factors, leading to suicide. Further, this paper also touches upon the nature and intensity of psychological distress of the survivors of farmers' suicide in their close proximity. On the whole, this paper touches adequacy and effectiveness of government compensations and waivers in combating the suicides by curbing the distress on all strata.

\section{REVIEW OF LITERATURE}

It is clear that the rural distress is real, with stagnant real incomes for farmers and declining wages, along with a slowdown in the non-farm sector. Rural distress has widened in the last decade, as input costs and wages have risen while incomes have remained stagnant. Madhya Pradesh, Karnataka and Assam government in between 2017 and2018 have waived many loans and fulfilled their promises but still there was no significant change in the agricultural growth.

Several studies and non-government reports on the suicides have identified the larger and broader factors that account for such distress. Some of the vital key issues that have been identified are - impact of neo-liberal economic policies including the incorporation of Indian agriculture into the world market (Shiva and Jafri 1998; Patnaik 2004, 2006); increasing costs of production (Vyas 2004, Mohanty and Shroff 2004); Lack of availability of credit including inadequate institutional; brake or non-acceleration in rural growth (Dev, 2004); dropping down of wages, increasing unemployment and indebtedness (Patnaik 2004; Dev 2004; Sarma 2004), continuous loss of production, and as results of a triple crisis of the economy, society, and ecology (Vasavi 1999).

Farmers had committed suicides in Karnataka due to low prices of agricultural produces and the absence of adequate debt in timely manner. Other than these reasons, farmer suicides include diminishing overall agricultural growth.

Agrarian crisis in India, amid other causes, has largely been debated as the prime reason for the current deteriorating state of farmers. Moreover, it has become important that (psychiatric) epidemiology and public mental health try to develop new mechanisms to understand and implement measures, and consider it while attempting health promotion and prevention (Anindya, 2011).

This paper tries to analyse the reasons for farmer suicides in India and deeper analyses, however, it reveals that there are various other reasons for increasing suicides, which are, small land holding, less institutional support, relying more on monsoon, price shocks, poor credit facility etc. (Anil \& Raghvendra, 2019).

Rural distress has widened in the last decade, as input costs and wages have risen while incomes have remained stagnant. In the case of cereals, primarily rice and wheat, a system of a Minimum Support Price (MSP) and a mechanism of procuring farmers' outputs through the Food Corporation of India and the state marketing federations have been in place in several states, assuring the farmer of a reasonable price for his output. However, the MSP has increased only this year after stagnating for three years during which farm incomes stressed (Narayan, 2018). 


\section{Hypothesis}

- Farmers' suicide in India is a consequential subject due to increasing psychological stress or factors pertaining to agrarian crisis.

- Farmers' suicide in India is directly proportional to various sociological factors pertaining to agrarian crisis.

- There happens to be a nexus between sociological and psychological factors pertaining to farmers' suicide and in most cases various sociological stressors lead to mounting psychological stress.

\section{Research Methodology}

We have basically relied on secondary data, i.e., various researches on agrarian crisis and farmers' suicide by using the term "farmers' suicide" and "agrarian crisis" on google and various online research material sites like ShodhGanga and ResearchGate.

Also, we have tried to collect as many as articles, newspaper opinion columns and reports published by national and international organizations related to such topics.

We did not limit our scope to India only, but also collected papers and articles regarding agrarian crisis and farmers' suicide around the world, especially Australia; which along with India, reports one of the highest numbers of farmers' suicide, though to study farmer suicides, we have taken Vidharbha region of Maharashtra as an example to conclude our research.

\section{Limitations}

For the topic being abstract, primary data could not be gathered through questionnaires or interviews. The fact that this paper was being researched by students, hence there was inability to get permission from local authorities to interview the farmers, as few of the researchers from national organizations did. Therefore, we had to basically rely on secondary data from various articles, and subsequently had to draw conclusions from already available sources only.

\section{Sociological Factors Contributing to Farmer Suicides}

Sociological factors mean those elements of society that radiates both positive and negative influence that affects or influences the society. India is a developing nation and despite of our rising GDP, India is a country where despite being a country whose GDP may be rising fast, India is a country where a major bunch of the rural population is hunger struck and struggling to find their basic ailment and per capita income is much lower compared to that of rich nations.

"Manjunatha and Ramappa (2017) have categorically attributed the following reasons to the incidents of farmer suicides in India - (1) social causes, (2) farm related causes and (3) debt related issues. Social in terms of the farming related causes can be lack of access to expected credit, non-realization of higher output and prices and crop failure etc. which are the major reasons for increasing farmer suicides in India. (Manjunatha, V, Ramappa, \& B, Retrieved February 19, 2019)." These sociological factors affect Agriculture that leads to pressure on farmers resulting in farmer suicides. Below are few of the sociological and economic factors that are the reasons for increasing farmer suicides and Agricultural distress. 


\section{Unpredictable Natural Events}

Natural events directly or indirectly are the root cause of Agriculture distress in India. Natural disasters are always unpredictable and even if they are predictable, it is very difficult to mitigate the damage caused by it. These events can be excessive rainfall, landslides, floods, drought etc.

The monsoon presently still remains the prime factor that keeps influencing Indian agricultural prospects and affecting it in a drastic manner. In June-September 2018 during monsoon, rainfall as a whole was $91 \%$ of the Long Period Average (LPA), indicating 'less than normal rainfall', although not a drought situation. In North-West India, Central India, South Peninsular India, and North-East India, rainfall was 98\%, 93\%, 98\% and 76\% of the respective LPA (Annual Report, 2018-19).

Flood that occurred in Kerala in August 2018 is the epitome to understand the impact on Agriculture. The flooding in Kerala was reported to have affected tea, rubber, cardamom and black pepper plantations which estimates up to 500 acres of plantation land, was being affected due to landslides in Malappuram, Nilambur and Kalikavu districts. According to one research, $80 \%$ farmland of India depends on flooding during monsoon season, so lack of adequate rainfall can cause droughts, implying crop failure more common (Parvathamma, 2016). Crop yields have declined in drought affected regions and food for cattle has become scarce. Agricultural regions that affected by droughts have experienced hike in their suicide rates.

\section{Indebtedness}

An average Indian farmer is always in debt as he has to work on an uneconomic holding using traditional methods of cultivation and being exposed to various other risks associated with poor agriculture season. He is a perennial debtor. Agricultural credit facility was always a concerning part for the government. This was the prime reason why government invested in Institutional sources to make agricultural credit easier and cheaper.

There are mainly two types of credit sources that is Institutional sources and non-institutional sources.

The prime motive of institutional credit is to help the farmers in growing their agricultural productivity as maximising their income. Institutional credit is productive in character. Below are some of the vital institutional sources of agricultural credit in India (Kwat, 2012). The examples of Institutional sources in India are-

Cooperative societies basically are primary agricultural credit societies that nearly cover the ambit of 86 per cent of the Indian villages and accounts for 36 per cent of the total rural population of the country.

Land development banks is another source which generally advance long term co-operative credit for 15-20 years to the farmers against the mortgage of their lands with an objective of its permanent improvement, purchasing agricultural equipment's and for repaying old debts. Similarly Regional Rural Banks were set up in 1975 for advancing direct loans to small and marginal farmers, agricultural labourers and rural artisans etc. for productive purposes. RBI generally directs the commercial banks to adhere to the policies made by the government. Thus these banks are approachable to farmers with the help of "village adoption scheme" and service area approach, these banks started to meet the credit and other requirements of the farmers.

Even after implementation of various institutions by the government, the farmers still continued to take credit from non-institutional sources. 


\section{DISTRIBUTION OF HOUSEHOLDS WHO TOOK ANY LOAN BY SOURCE OF LOAN (IN PERCENTAGE)}
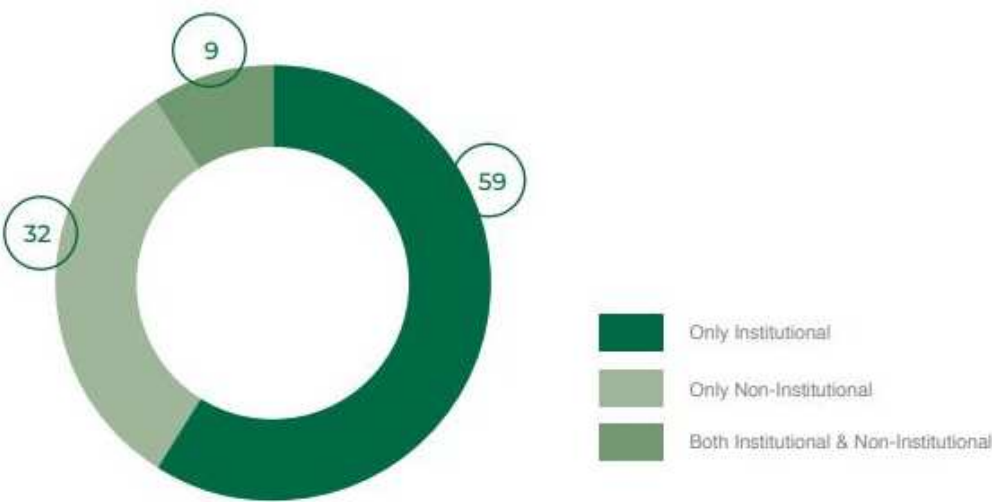

Source: NABARD all India Financial Report 2016-2017

\section{Interpretation}

From the above graph, it can be interpreted that the farmers still prefer to take loans from Non-institutional rather than institutional sources. So, two things can be interpreted that farmers, rather prefer to take loan from non-institutional sources or they are not aware of institutional sources and advantage. The reports and surveys show that there is lack of awareness in the farmers about the merits of Institutional sources. The farmers in rural areas are still being influenced by the moneylenders and thus they never try to find out about various Institutional sources set up by the government. Below statistical data defines categorization of state on the basis of average outstanding debt.

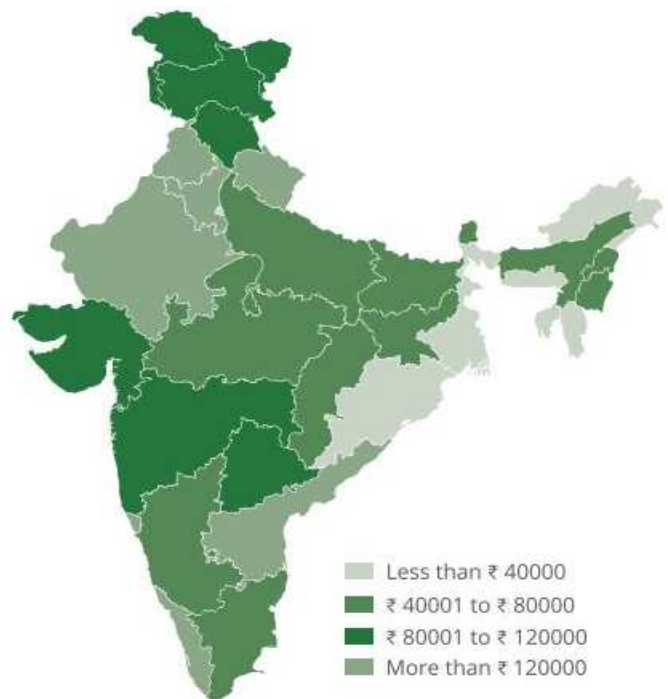

Source: NABARD all India Financial Report 2016-2017.

Although the farmers prefer to avail credit facility through Non-institutional sources/private sources, but these sources have few defects that are responsible in exploiting the farmers and negatively influence the agriculture (Suman, n.d.).

The defects are as following -

- It is highly exploitative in character as they inherit profit motive rather than social welfare.

- The rate of interest charged to avail credit facility is high as this credit is for unproductive purpose. 
- Such credit is not necessarily directed to-ward needy persons or desired channels.

- Such credit is provided for short periods of time and at high rates of interest and cannot, therefore, be utilised for land development or long- term improvement of agriculture.

- Institutional credit is not linked with other non-farm services such as marketing and processing and warehousing.

\section{Low level of Income of Small Farmers}

Whenever the government talk about reviving economic growth, agriculture is seldom ignored. Condition of agriculture can be seen in the flurry of recent policy announcements that are cut in corporate tax, recapitalisation of banks bank mergers, cut in the GST, higher depreciation on vehicles etc. Share of agriculture in the announcements is negligibly seen.

In India, irony is that agriculture holds very little share in the announcements by the government, whereas it remains the biggest source of livelihood for farmers and it is the depression in consumer demand, specifically in rural areas is dependent largely on agriculture. Evidently, it can be construed that there is no diversification whereas the income of an average farmer household (by cultivation) remains low.

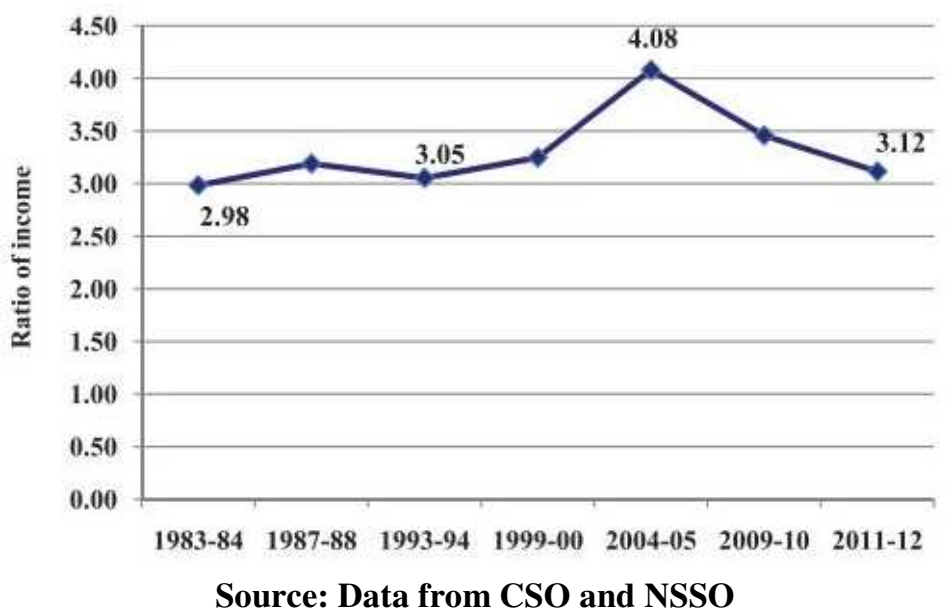

\section{Interpretation}

From the above graph, it can be interpreted that the ration of income between non-farmers and cultivators remains high. Low level of income of farmers and deteriorating disparity between non-farmers and cultivators was a vital and prime reason for agrarian distress in 1990's. If the income of farmers continues to remain low, then agrarian distress would continue, leading in declining GVA and GDP of India.

The government is now focusing on doubling the farmer's income by 2022. Prime Minister Narendra Modi recently in Kissan rally being organized in Bareilley talked in favour of doubling farmer's income by 2022 although the target seems unachievable according to few researchers.

\section{Declining Growth Rate in Agriculture}

GDP post-independence though started to gradually increase but overall, there was no growth in agricultural sector. First Five Year plan was dedicated to implementation of various agricultural policies and achieve growth in Agriculture, but no significant change happened. Later on other five years plans talked about growth in agriculture but it remained all on paper and not became practical. Statistics shows that not only the contribution made by the agricultural sector to the overall GDP 
has declined but also the growth of agriculture sector itself is declining gradually.

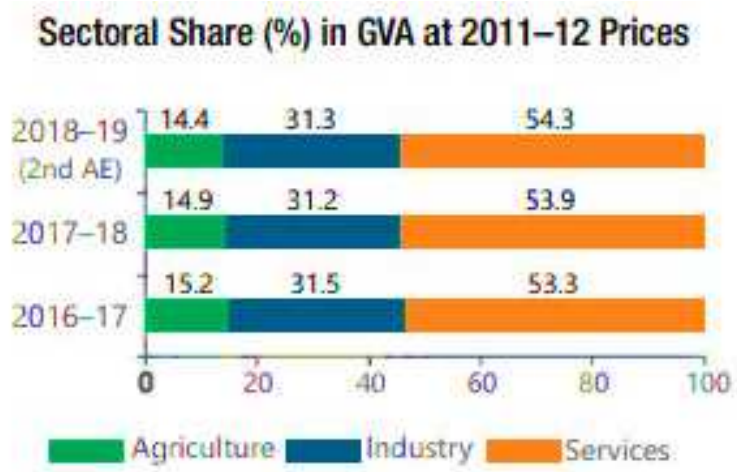

Source: Provisional Estimates of Annual National Income 2018-19, Central Statistics office, Ministry of Statistics and Programme Implementation.

\section{Interpretation}

From the above graph, it can be interpreted that the share of agriculture in Gross Value Added (GVA) continues to remains low and on the other hand, the share of Service sector in the Indian economy continues to rise. Since 1947, the share of agriculture have not increased much which is a great matter of concern for the Indian Economy as most of the Indian Population still depend on agriculture for their sustainability.

\section{Other Factors}

\section{Falling Private Investment}

For any development, investment is of prime importance as more investment leads to better usage of resources and development of the sector. National Agriculture Policy, 2000 took initiative to improve private investment. Statistical data proves the point.

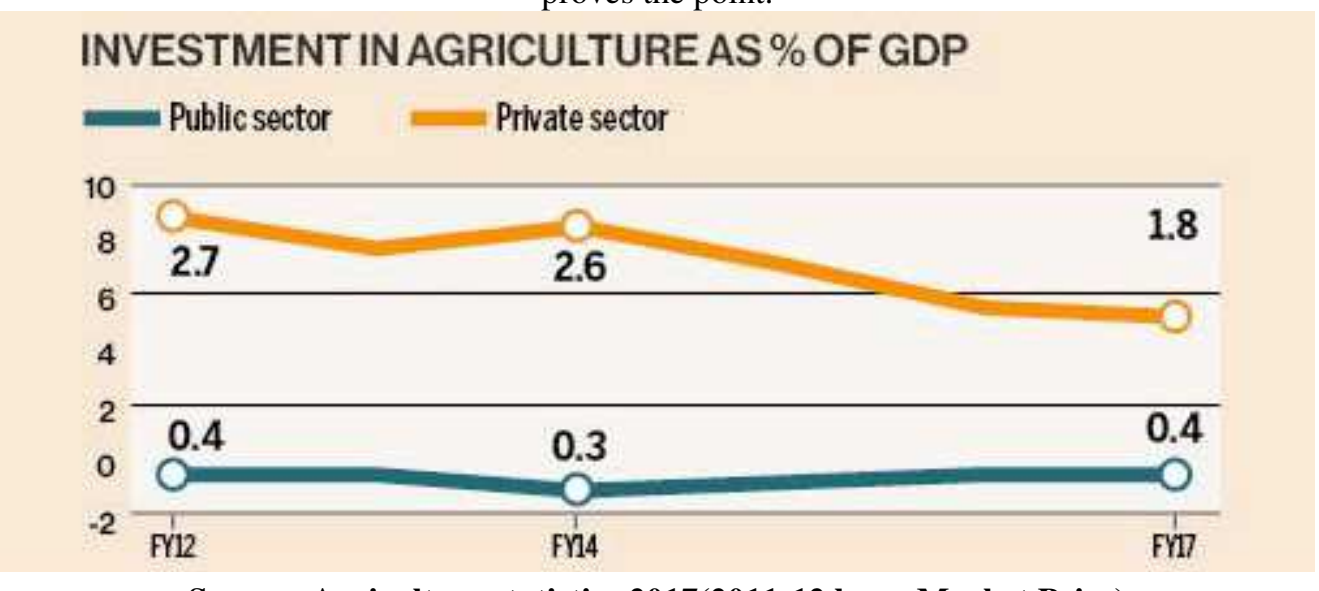

Source: Agriculture statistics 2017(2011-12 base, Market Price)

\section{Interpretation}

From the above, it can be interpreted that Investment in Agriculture (as Percent of GDP) has declined over the years. Public investment remained less static at $0.3-0.4 \%$ of the GDP while private investment fell from $2.7 \%$ to $1.8 \%$, dragging down the overall investment from $3.1 \%$ to $2.2 \%$ of the GDP.

\section{Diversion of credit for non-agricultural use}


Diverting the credit given for agricultural purpose to non-agricultural purpose is a major issue. Farmers when asked about why they use the credit for other purposes they come up with the excuses that they require money for their children's marriage, sustaining family, paying debt etc. The RBI's internal working group report reveals that there are few states that are getting agri-credit, that is far higher than their entire agri-GDP which implies there has been diversion of credit for nonagricultural purposes. On the other side of the coin, there are few states that are getting significantly higher credit than their usual input costs like Andhra Pradesh (7.5 times), Kerala (6 times), Goa (5 times), Telangana, Tamil Nadu and Uttarkhand (4 times) - raising questions about its use. (Mohanty, 2019)

Many researches have been conducted so far which reveals that resources are used for non-agricultural purposes is due to high arbitrage (gap) in interest rates for the agriculture and other sectors. Farmers receive a concessional interest rate of $7 \%$ particularly for the short term crop loans, $2 \%$ interest subvention and near about $3 \%$ repayment incentive which makes effective rate of interest to be $4 \%$ while for other sectors, the rate is $10 \%$ or more. As long as this gap is present, the diversion would continue to rise.

Other influential factors could be employment, low wage rates etc. Though various schemes like MGNREGS was launched for farmers to get employment, yet it had found few shortcomings. The MGNREGS presently suffers from two prime problems- (i) the wage rates are below the minimum wages of corresponding states, (ii) the central budgetary allocations are lower compared to the actual expenditure for the past recent years.

\section{Psychological Factors Pertaining to Farmers' Suicide}

Worldwide, suicide happens to be the one of the three indigenous causes of death amongst people aged 15-44 years, followed by the second leading cause of demise amongst 10-24 years age group (Bertole \& Fleischmann, 2002). Every year, suicide happens to be the root cause of death for about one million people; thereby, indicating 16 per 100,000 as the "global" mortality rate (Mental Health Suicide Prevention , 2015). Mental illness happens to be a thorough-researched factor of danger for suicide (Cavanagh, Carson, Sharpe, \& Lawrie, 2003).

Farming as an vocational strata for livelihood reclines a high risk of suicide. Although the occupation of farming mostly comes off with the tag of a healthy and serene way of life, yet agriculture as an industry has the highest mortality rate if put to comparison with other vocational industries (Mc curdy \& Carroll, 2000). Data shows that in few farming communities, suicide rates take a straight surge than the general population. Nevertheless, statistics from the extant literature remains largely inconclusive as to whether mental health problems happen to be over-represented in these communities. (Fraser CE, 2005) Furthermore, as evident from the researches of Sainath and Menon (Menon, 2001), many of these farmers' suicide are not counted only because of them either being landless farmers or women farmers, therefore keeping them out of the data. Studies have highlighted various parts of India in coherence to farmers' suicide, with some asserting that South India being the hot-bed of such suicides while most of them asserted the Vidharbha region of Maharashtra being the most farmers' suicide-prone area in India (Mc curdy \& Carroll, 2000). Incepting with early 1990's, there seems to be a stark surge in the total statistics (numbers) of farmers' suicides in India (PB Behere, 2009). A newer research based on the National Crime Reports Bureau (NCRB) data conducted by Prof. K. Nagaraj of the Madras Institute of Development Studies intends towards a proliferating figure of farmers' suicide, near about 1.5 lakh farmers in confirmation, during the period of 1995 to 2005. Though it is implausible to assert that NCRB publishes a full range of data, but general overview indicates a succumbing public health issue. Myriad of research shows that the total suicide statistics in the general population are inherently under-reported succumbing to fear of legal and social ramifications, 
indicating uneven and distorted standards in certification and lax record-keeping by the government authorities actually impaired by prejudices, biases and corruption. Therefore, the incidence figures in government records (which indicate national annual average to be standing around 11 per 100,000 population) are much lower than recent community-based verbal autopsy studies. (Anindya, 2011).

Idiosyncrasies related with farming as a vocation is intrinsically linked with farmers' suicide in India (Mc curdy \& Carroll, 2000). And studies regarding causes of such suicides have mostly focussed themselves on the economic and political aspects pertaining to suicides, while mostly ignoring the psychological factors behind commission of such suicides. "In India there was a schism in research approach. PubMed articles were published by professionals from mental and public health. Humanities' stream had abundant literature focusing on the economic and political factors paving the way for farmers' suicides. The mental health aspects were not taken into consideration. The qualitative and verbal psychological autopsy studies from India. We did not come across personnel from medical and non-medical streams conjointly involving in research regarding farmers' suicide in India." (Smitha Ramadas, 2017). However, few of the research papers have focussed on the psychological factors, some superficially, while some have done in-depth analysis. We have also come across research pieces where psychological distress of the survivors from the farmer's family who committed suicide was studied in depth.

Studies reveal that to a large extent, most of the suicides associated with the vocation of farming finds its origin with an amalgamation of a number of factors, viz., being both a part of group and at individual level. Hand-on field researches in Western Vidharbha (Mishra, 2006), along with sundry districts of Vidharbha, Marathwada and Khandesh (Tata Institute of Social Sciences, 2005) regions (in the state of Maharashtra) have conjointly measured and analysed the factors (Mishra, 2006). To substantiate, the factors in a descending order of magnitude are estimated as: indebtedness (93\%-87\%); remunerative (economic) deposition (74\%); domestic conflicts/trifles (55\%); failure in crop production (41\%); indentation associated with social status (36\%); daughters/sister's nuptial arrangements(marriage) (34\%); suicide committed in the immediate neighbourhood or within the family (32\%); addiction (28\%); and health ailments (inclusive of problems pertaining to mental health) (21\%) (Causes of Farmer Suicides in Maharashtra: An Enquiry, 2005). Studies revealed that the addiction factor is comparatively on a higher level in the state of Kerala (alcohol addiction 43\%) as opposed to other states (Shreyas, 2006). However, the list of factors mentioned above is not exhaustive, since there also happens to be the less-frequent factors, such as: dearth of income from subsidiary vocations/occupations; comparatively weak co-operative movement; unwillingness of landed farmers to go for Employment Guarantee Scheme work; illness of one's oneself or somebody else within the family; and domestic trifles (Mc curdy \& Carroll, 2000). Therefore, we see these studies have done in-depth analysis of other factors but the ratio of the contribution of mental health issues has been callously coupled with other somatic/bodily problem and is seen as a separate entity/cause for contributing to farmers' suicide; which implies that these studies fails to establish any relation between the factors discussed above, i.e., political, social, economic, etc. with mental distress; eventually leading farmers' to commit suicide. This issue has been addressed by one study in International Journal, which mentioned, "What is more unique to Indian setting is, unlike in the West, suicides are often related to pre-existing chronic socioeconomic stress, interpersonal, social and cultural conflicts." (Prasad, et al., 2006) Also, regarding method of suicide, the most economic and convenient method to commit suicide by the farmers were found to be use of pesticide. A detailed study of which is found on the table below comparing farmers' suicide and farmers' suicide using pesticide against total suicide from 1997 to 2005. 


\begin{tabular}{|c|c|c|c|c|}
\hline Year & $\begin{array}{c}\text { Total no. of } \\
\text { suicide }\end{array}$ & $\begin{array}{c}\text { The total rate of } \\
\text { suicide (per 100,000 } \\
\text { pop.) }\end{array}$ & $\begin{array}{c}\text { Percentage of farmers' } \\
\text { suicide in totality (\% of total } \\
\text { suicide) }\end{array}$ & $\begin{array}{c}\text { Percentage of farmers' suicide due } \\
\text { to pesticide poisoning (\% of total } \\
\text { suicide) }\end{array}$ \\
\hline 1997 & 95,829 & 10.0 & 14.2 & 19.1 \\
\hline 1998 & 104,713 & 10.8 & 15.3 & 15.3 \\
\hline 1999 & 110,587 & 11.2 & 14.5 & 20.3 \\
\hline 2000 & 108,593 & 10.6 & 15.3 & 19.8 \\
\hline 2001 & 108,506 & 10.6 & 15.1 & 19.4 \\
\hline 2002 & 110,417 & 10.5 & 16.3 & 20.8 \\
\hline 2003 & 110,851 & 10.4 & 15.5 & 20.5 \\
\hline 2004 & 113,914 & 10.5 & 16.0 & 19.6 \\
\hline 2005 & 113,914 & 10.3 & 15.0 & \\
\hline
\end{tabular}

Source: Various issues of Accidental Deaths and Suicide in India, National Crime Records Bureau (adapted from

Sainath, 2007a.)

Interestingly, studies also reveal that with a large number of farmers committing suicide, there happens to be an equal or more number of people left behind, who become prone to inducing negative outcomes in themselves, thereby triggering mal repercussions in the family (Ratanarajah D, 2008). Thus, considerably higher rates of anxiety, depression, and pathological grief along with toils in maintaining a healthy social life have been studied and found amongst suicide survivors (McMenamy, Jordan, \& Mitchell, 2008). Moreover, in one case-control study to examine and assess the psychological distress among survivors of psychological distress using Self-Reporting Quesnnarire-20 (SRQ-20), with the statistical data being analysed with the use of Chi-square or Fisher's two-tailed exact test ( typically used for assessing class variables) ; it was found out, "Sixty-one (62.2\%) farmers' suicide survivors had psychological distress (total SRQ -20 score $>/ 10$ ) compared to $20(20.4 \%$ ) of controls (odd ratio $[\mathrm{OR}]=6.3,95 \%$ confidence interval $[95 \% \mathrm{CI}]=3.3-12.2, \mathrm{p}<$ 0.001). Nearly, one-third (30\%) of the survivors had total SRQ-20 scores between 15 and 20 as compared to only 5\% of the general population controls." (ManikChangojiBhise, 2016)

Through this study, other subsidiary, but important details were also listed out. They were: Age of survivors did not have a significant correlation with the presence of psychological distress $\left(\mathrm{x}^{2}=6.8\right.$, $\left.\mathrm{df}=4, P=0.1\right)$. Of all, female survivors $(\mathrm{n}=61), 78.69 \%$ were psychologically distressed compared to only $35.1 \%$ of all male farmers' suicide survivors (risk ratio $[\mathrm{RR}=2.1,95 \% \mathrm{CI}=1.4-2.9, \mathrm{P}<0.001$ ); surviving spouses were significantly were more likely to have psychological distress than other relatives of suicide victims $(\mathrm{RR}=2.1,, 95 \% \mathrm{CI}=1.4-2.9$, $\mathrm{p}<0.001)$; there was no difference in psychological distress among those who were below or above poverty line $(\mathrm{RR}=0.9,95 \% \mathrm{CI}=0.6-1.3, P$ $=0.4)$; there was no significant difference in the presence of psychological distress in survivors of suicide victims who committed suicide by violent method as compared to survivors of those who used non-violent method $(\mathrm{RR}=1.04,95 \% \mathrm{CI}$ $=0.75-1.45, P=0.3)$ (ManikChangojiBhise, 2016).

However, government's compensation for those families had hardly brought any change in the suicidal tendency or psychological distress prevailing in the farmers' families as only $45 \%$ of the survivors had received some kind of government aid. There was no difference in the presence of psychological distress among those who did not receive government aid (Ex-gratia financial help) and those who received it $(\mathrm{RR}=0.8,95 \% \mathrm{CI}=0.36-1.91, P=0.3)$ (ManikChangojiBhise, 2016). However, studies have also shown that providing relief to families of deceased farmers had led to paradoxical effect (SM). Farmers committed suicide to enable financial assistance to the families (Thapaliya, 2009). 
Moreover, a qualitative and in-depth study from South India depicts that most of the families with a financial crisis and the instance of suicide in the family gets stigmatized and equally ostracized by the surroundings, leading to social isolation at times (Manoranjitham, et al., 2007). While, in addition, the presence of psychological distress happens to be associated with substantially increased socio-economic impairment (Cardozo BL, 2004). This compounding relationship between psychological distress and socioeconomic dysfunction leads to long-term impairments in family functioning delaying recovery of survivors from grief. After a period of heightened grief, families and survivors take years to cope with the loss. Thus, even after 2 to3 years, farmers' suicide survivors were still experiencing significant psychological distress (Saarinen PI, 2002). Expression of suicide ideas by almost one-third of survivors was another alarming finding. Similar high proportion of survivors having suicide ideation was recently reported by McMenamy et al (McMenamy, Jordan, \& Mitchell, 2008). Thus, farmers' suicide does not end with the demise of a farmer but it creates burgeoning suicidal tendency for his/her/their survivors; thus continuing the perpetual and vicious cycle.

Also, it is evident from the above mentioned facts that the social status of farmers and their treatment being a separate and exclusive class from the normal strata of the society has got to do lot with the psychological distress that persists with the famers' community. Besides, a research study in Indonesia indicated the rates of CMD in accordance with the levels of economic development in villages and asserts changes in these levels in the 1980s. Development was studied according to ascriptions, viz., means of sustenance, education, community co-operation and participation, and means of commute (the developed villages, the better amenities). The villages which have accomplished an ameliorated rate in development status and those villages that were already at the utmost level of development had the least rates of mental disorders. (Bahar, 1992)

On the whole, farmers' suicide should not be only left to be seen as a mental health issue only. A comprehensive study linking all the factors, viz., economic, political, sociological as well psychological needs to be done together; having said that, we automatically conclude that all these factors are not mutually exclusive and deviation of one factor leads to disturbance of the other, thereby continuing the loop of suicide of farmers'. A comprehensive approach to suicide would also reduce stigma, which is one of the factors which prevent people from disclosing and seeking help (Rüsch N, 2014). Moreover, the present strategy of Indian Government to provide solely financial help to suicide households, though it being an essential step in itself, does not seem to be effectively working out and an overall comprehensive strategy involving psychological, social, and economic interventions is much required (ManikChangojiBhise, 2016).

\section{Nexus between Sociological and Psychological factors Pertaining to Farmers' Suicide}

Sociological factors and Psychological factors are directly related to each other. Though it is difficult to form a reasonable nexus between the two, but still by the research conducted, it can clearly be interpreted that Psychological factors are the results of Sociological Factors. They both are interdependent.

Sociological factors like Indebtedness forces farmers into a spiral debt trap which is difficult for the farmers to escape. Natural Disasters on the other hand contributes in damaging the cultivated land of the farmers which basically leads to low level of farmers. Income plays a major role, low level of income leads to unsustainability of farmers. The farmers are not able to afford basic ailment and facilities due to low income which attributes various other factors for the farmers that include unable to organize marriage of their children's, loss of status in the society etc. which unfortunately force them for suicides. 
Thus, it can be observed that Psychological factors are the result of Sociological factors which concludes that our Hypothesis is partially satisfied.

\section{CONCLUSIONS}

Thus, on the whole, it has been proven by various secondary research data that both sociological factors like indebtedness, inability to pay interest, prolonged drought, increase in the cost of inputs while getting a lesser output for produce plays an important role in leading farmers towards suicide. Moreover, all these sociological factors are in close proximity with various psychological factors like headaches, uneven sleep patterns, stomach problems, i.e., onset of depression and other related mental prognostications. Importantly, the societal status of farmers as a distinct class and lack of support from community contributes much to this psychological morbidity. Further, it is also found out that the close relatives, i.e., survivors of the dead farmers are more prone to acquiring psychological distress, thereby continuing the perpetual hoop. Surprisingly enough, the compensations and waivers given to the farmers' family in case of death has acted as an incentive for farmers to commit suicide and stabilize their family economically; thus it acted as a paradox rather than a positive step from the government. Therefore, in spite of all the efforts, the farmer's suicide still takes a burgeoning curve in an agrarian economy like India since there is no real assessment as to the biological and psychological factors/stressors leading to such suicides. On the whole, if the government has to really work towards curtailing farmers' suicide rate, it would have to work in detailed manner on the internal psycho factors which in turn governs the other sociological factors on a large scale, rather than providing mere monetary compensations and waivers. Thus, through study, it can be concluded that Hypothesis 1 and 2 are satisfied and Hypothesis 3 is partially satisfied as there is no quantitative evidence of proving the nexus between the two factors.

\section{SUGGESTIONS}

There needs to be more robust and systematic approaches to be followed in India, for e.g., detailed case-control study of psychiatric distress in farmers at large, thereby locating the real reasons behind farmers' suicide, thereby forming a reasonable nexus with the sociological and economical distresses pertaining to suicide. Thus, the complex intertwining of biological and psychological issues needed to be examined in detail or to be made into a governmental report through a governmental commission to generate a novel hypothesis, thus, providing an effective solution. Besides, since farmers' suicide do not stop there with only one farmer committing the suicide but also triggering a continuous chain of suicide in the family of such farmer, thereby continuing the malicious labyrinth; government can set up agencies for psychological counselling or therapy of those survivors and also can come up with ideas like adopton of the particular village by well-todo human being or organization; As lack of economic development or per se development on the whole creates an impact on the mind of the survivors, and mostly that happens to be a negative impact. Also, more of research should be conducted on this area of study using innovative research methodologies to bring this aspect of the plight of farmers into limelight, rendering better community action.

\section{ACKNOWLEDGEMENT}

I, Poushali Chakraborty and Vedant Dubey are BBA LLB (Hons.), second year students from NarseeMonjee Institute of Management Studies (NMIMS) Navi Mumbai School of law and have conjointly worked towards making this paper both meticulously and harmoniously. 
Putting forth this research paper has taken us lot of sincere efforts and help and support of other people. We want to sincerely thank our Economics faculty of NMIMS Navi Mumbai, Dr. Chandan Singh Adhikari, who was not only supportive of our work, but also constantly pestered to move ahead by doing numerous corrections in the paper, rough draft and structure of the paper as a whole. Therefore, we sincerely thank Mr. Chandan Singh Adhikari for all his support and help.

\section{REFERENCES}

1. Anil, K., \&Raghvendra. (2019). Farmers suicides in India-Challenges and remedies. Economic Affairs, 64, 387-394.

2. Anindya, D. (2011). FARMERS' SUICIDE IN INDIA: IMPLICATIONS FOR PUBLIC MENTAL HEALTH. International journal of Social psychiatry, 57(1).

3. (2018-19). Annual Report. New Nelhi: NABARD. Retrieved https://www.nabard.org/auth/writereaddata/tender/3107191001NAR\%202018-19\%20(E),\%20Web-RGB\%20(Checked\%20\%20Final),\%202019.07.29,\%200830hrs.pdf

4. Bahar, E. H. (1992). An epidemiological study of mental health and socioeconomic conditions in Sumatera, Indonesia. Acta Psychiatrica Scandinavica, 85, 257-263.

5. Bertole, J., \& Fleischmann, A. (2002). Suicide and psychiatric diagnosis: a worldwide perspective. World Psychiatry, 1.

6. Cardozo BL, B. O. (2004). Mental health, social functioning, and disability in postwar Afghanistan. JAMA, 292:575-84.

7. (2005). Causes of Farmer Suicides in Maharashtra: An Enquiry. Tata Institute of Social Sciences.

8. Cavanagh, J., Carson, A., Sharpe, M., \& Lawrie, S. (2003). Psychological autopsy studies of suicide: a systematic review.Psychol Med.

9. Das, A. (n.d.). Farmers' suicide in India: Implications for public mental health.

10. Dev, M. (2004). How to Make Rural India Shine. Economic and Political Weekly.

11. Fraser CE, S. K. (2005). Farmimg and mental health problems and mental illness. Int J Soc Psychiatry., 51, 340-9.

12. JM, B., \& A, F. (2002). Suicide and psychiatric diagnosis: a worldwide perspective. World Psychiatry, 181-5.

13. Kwat, N. (2012). Essay on Agricultural Credit in India. economic discussion. Retrieved from http://www.economicsdiscussion.net/essays/essay-on-agricultural-credit-in-india/18098

14. ManikChangojiBhise, P. B. (2016). A case-control study of psychological distress in survivors of farmers' suicides in Wardha District in Central India. Indian Journal of Psychiatry, 148-149.

15. Manjunatha, V, A., Ramappa, \& B, K. (Retrieved February 19, 2019). Farmer Suicides: An all India Study. New Delhi: Department of Agriculture, Cooperation \& Farmers Welfare, Government of India. Retrieved from http://www.isec.ac.in/farmer_suicides_An all India study-09Aug2017-revised.pdf

16. Manoranjitham, S., Charles, H., Saravanan, B., Jayakaran, R., Abraham, S., \& Jacob, K. (2007). Perceptions about suicide: A qualitative study from Southern India. Natl Med J India(20), 176-9.

17. Mc curdy, S., \& Carroll, D. (2000). Agricultural injury. Am J Industrial Med.

18. McMenamy, J., Jordan, J., \& Mitchell. (2008). What do suicide survivors tell us they need? Results of a pilot study. Suicide Life Threat Behav.

19. Menon, P. (2001). A farm crisis and suicides. Frontline. Retrieved from 
http://www.hinduonnet.com/fline/f11808/18080210.htm.

20. (2015). Mental Health Suicide Prevention. WHO.

21. Mishra, S. (2006). Farmers' suicides in Maharashtra. Economic and Political Weekly.

22. Mohanty, P. (2019, September 27). Decoding Slowdown: Govt apathy and low investment continue to plague the agriculture sector. Business Today. Retrieved from https://www.businesstoday.in/sectors/agriculture/decoding-slowdown-agriculturesector-govt-apathy-low-investment-plagues-farmers-income/story/381618.html

23. Narayan, S. (2018). Farm distress in India- Causes and possible Remedies. Institute of Asian Studies, pp. 1-10.

24. Parvathamma, D. G. (2016). Farmers Suicide and Response of the Government in India -An analysis. IOSR Journal of Economics and Finance, 7(3), PP 01-06. Retrieved from http://www.iosrjournals.org/

25. PB Behere, M. B. (2009). Farmers' suicide: Across culture. Indian J Psychiatry.

26. Prasad, J., Abraham, V., S, M., Abraham, S., Joseph, Muliyil, J., \& Jacob, K. G. (2006). Rates and factors associated with suicide in Kaniymbadi Block, Tamil Nadu, South India.

27. Ratanarajah D, S. M. (2008). Survivors' narratives of the impact of parental suicide. Suicide Life Threat Behav, 38: 618-30.

28. Rüsch N, Z. A. (2014). Does the stigma of mental illness contribute to suicidality? Br J Psychiatry, 205; 257-9.

29. Saarinen PI, H. J. (2002). Mental health and social isolation among survivors ten years after a suicide in family: A case control study. Arch Suicide Res, 6:221-6.

30. Sainath, P. (2007). Farm suicides rising, most intense in four states. The Hindu. Retrieved from http:///www.thehindu.com/2007/11/13/stories/2002081100500100.html

31. Shreyas. (2006). Agricultural Crisis and Debt suicide in Wayanad. Sultan Bathery, Wayanad, Kerala: Shreyas.

32. SM, W. (n.d.). Suicide of farmers in Maharashtra-Causes and remedies. Mumbai AC.

33. Smitha Ramadas, P. K. (2017, January). Farmers' suicide and mental disorders perspectives in research approachescomparison between- India and Australia. ResearchGate, 304-305.

34. Suman, S. (n.d.). Problems of Agricultural Credit in India (with Suggested Remedies). Retrieved from economics discussion: http://www.economicsdiscussion.net/agriculture/problems-agriculture/problems-of-agricultural-credit-in-india-withsuggested-remedies/12852

35. Tata Institute of Social Sciences, R. C. (2005). Causes of Farmer Suicides in Maharashtra: An Enquiry. Mumbai (submitted to Mumbai High Court): Tata Institute of Social Sciences, Rural Campus.

36. Thapaliya, B. (2009). India's Dilemma: Farmer's rising suicide rate. Retrieved from globalpolitician: http://www.globalpolitician.com/23847

37. Prasidha, P., \& Asokhan, M. Adoption Of Risk Management Strategies Amidst Paddy Farmers Of Cauvery Delta Zone In Tamil Nadu.

38. Ramasubramanian, M., Velusamy, R., \& Beaulah, A. The Development of Linkages And Value Chains for Sustainable Farmer Producer Companies: Evidences from Southern Districts of Tamil Nadu, India.

39. Duhan, A., \& Dhingra, M. (2018). Association between the factors affecting awareness level of farmers about agriculture insurance in Haryana. Int. J. Bus. Gen. Manage, 7(1), 17-24.

40. Darwis, I. Extension about the Groundwater Conservation and its Influence on Farmers Knowledge and Attitude in Takalar Regency, Indonesia. 